\title{
The influence of corticosteroid treatment on the OPG/RANK/RANKL pathway and osteocalcin in patients with pemphigus
}

\author{
Marlena Chmielnicka, Anna Woźniacka, Jolanta D. Torzecka \\ Department of Dermatology and Venereology, Medical University of Lodz, Lodz, Poland \\ Head of Department: Prof. Anna Woźniacka MD, PhD
}

Postep Derm Alergol 2014; XXXI, 5: 281-288 DOI: 10.5114/pdia.2014.44016

\begin{abstract}
Introduction: Pemphigus is a rare autoimmune blistering disease, which requires prolonged administration of corticosteroids at high doses. Although this therapy improves the health and lives of patients, it may have various side effects, for example osteoporosis.

Aim: To assess the concentration of osteoprotegerin (OPG), the soluble receptor activator of nuclear factor- $\kappa \beta$ ligand (sRANKL) and osteocalcin in patients with pemphigus.

Material and methods: The study comprised a group of 29 patients with pemphigus (17 women and 12 men) aged between 23 years and 75 years treated from 1994 to 2009 in the Department of Dermatology and Venereology, Medical University of Lodz, as well as 24 healthy volunteers matched appropriately in terms of gender and age.

Results: In patients with pemphigus, the mean osteoprotegerin concentration was up to $16.46 \%$ higher than in the control group. The average RANKL concentration in serum of patients with pemphigus was $26.88 \%$ higher. However, the patient group demonstrated a significantly lower concentration of osteocalcin by up to $18.03 \%$.

Conclusions: Under corticosteroid treatment, RANKL, which is released by osteoblasts, links with the RANK specific osteoclast receptor and stimulates osteoclastogenesis. This reaction can be blocked by osteoprotegerin, which is a competitive inhibitor to the same receptor site. A decreased osteoblast activity stimulates bone loss. The reduced level of osteocalcin, which is regarded as a marker for bone formation, and a simultaneously elevated RANK level reveal the promotion of osteoclast proliferation in patients treated with corticosteroids.
\end{abstract}

Key words: pemphigus, corticosteroids, OPG/RANK/RANKL pathway, osteocalcin.

\section{Introduction}

Pemphigus is an acquired autoimmune blistering disease, characterized by a chronic course and a serious prognosis. The disease requires long-term corticosteroid (CS) therapy which is administered in high doses.

Although this therapy improves the health and lives of patients, it may, however, have various side effects. Despite many attempts to combine its application with adjuvant therapy, intravenous immunoglobulins and more recently, monoclonal antibodies directed against proteins and cytokines, a combination of systemic corticosteroids with immunosuppressants is still the method of choice $[1,2]$. The mortality of pemphigus was $75 \%$ on average before the introduction of corticosteroids in the early 1950s [3-5]. This therapy resulted in a dramatic fall in mortality to an average of $5-10 \%$, but in most cases, the patient still experiences the side-effects of prolonged immunosuppressive treatment $[3,6]$. The most common adverse effects include hypertension, hyperglycemia, peptic ulcer disease, hypercholesterolemia, symptoms of Cushing's syndrome, and susceptibility to infections.

A high risk of developing secondary osteoporosis and bone fractures also exists [7-9]. The phenomenon of the progressive deterioration of the bone tissue microarchitecture during corticosteroid therapy in patients with pemphigus was noticed and described in the nineties of the last century by Stazi and Stazi [10]. The scale of the problem was underlined also by Chmurova and Svecova (2009) in their retrospective analysis involving 31 patients with pemphigus vulgaris. The authors point to the high percentage of occurrence of osteopenia and/or osteopo-

Address for correspondence: Marlena Chmielnicka MD, Department of Dermatology and Venereology, Medical University of Lodz, 1 pl. Hallera, building no. 6, 90-647 Lodz, Poland, phone: +48 42686 79 81, +48 501898 177, e-mail: marlena_chmielnicka@tlen.pl Received: 20.03.2014, accepted: 24.03.2014. 
rosis, of up to $41.9 \%$, in patients treated with systemic corticosteroids [11].

The pathogenesis of corticosteroid-induced osteoporosis is induced by several mechanisms but not fully elucidated. The combination of these mechanisms leads to increased bone resorption and prominently diminished bone formation. It is likely that corticosteroid treatment induces bone metabolism through the RANK/RANKL/OPG (receptor activator of nuclear factor $\kappa \beta /$ receptor activator of nuclear factor $\kappa \beta$ ligand/osteoprotegerin) pathway.

The RANKL released by osteoblasts, combines with a specific receptor, RANK, located on the surface of target cells, osteoclasts, and induces their differentiation, maturation and activation. This interaction may be blocked by osteoprotegerin, a protein produced by osteoblasts, which is regarded as a competitive inhibitor for the same receptor site. Binding to RANKL osteoprotegerin inhibits osteoclastogenesis and prevents the destruction of bone tissue. These feedback mechanisms create a balance between bone formation and destruction. Corticosteroids increase RANKL expression and decrease the OPG level, which finally boosts the process of bone resorption [8, 12]

Osteocalcin, which is secreted solely by osteoblasts, is regarded as a sensitive marker of bone formation. This non-collagenous protein, composed of 49 amino acids, stimulates bone building and mineralization.

\section{Aim}

As corticosteroids influence bone metabolism by reducing the number and function of osteoblasts and increasing the function of osteoclasts $[8,13]$, the aim of study was to assess the concentration of osteoprotegerin, soluble receptor activator of nuclear factor- $\kappa \beta$ ligand (SRANKL) and osteocalcin in patients with pemphigus, undergoing long-term systemic corticosteroid therapy.

\section{Material and methods}

The study comprised a group of 29 patients with pemphigus (17 women and 12 men) aged between 23 years and 75 years (mean age of 57.4 years) treated from 1994 to 2009 in the Department of Dermatology and Venereology, Medical University of Lodz, as well as 24 healthy volunteers matched appropriately in terms of gender and age. The exclusion criteria for selection comprised the presence of hyperthyroidism, inflammatory diseases and cancers, leukemia, multiple myeloma, and chronic renal failure, as well as the use of anti-epileptic drugs, tranquilizers and sleeping pills. The diagnosis of pemphigus was established on the basis of the clinical picture, and histopathology, as well as direct and indirect immunofluorescence. Twenty-four patients suffered from pemphigus vulgaris (PV) and 5 - pemphigus foliaceus (PF). The therapy of choice was the use of corticosteroids in combination with cyclophosphamide. The treatment of PV proceeded in three stages: intensive (prednisone 100$80 \mathrm{mg}$ per day, prednisone $100 \mathrm{mg}$ per day), refresher (prednisone 70-40 mg per day, cyclophosphamide 100$50 \mathrm{mg}$ per day, every other day) and maintaining (prednisone 30-10 mg per day, 2-3 times a week). In 5 patients with pemphigus foliaceus lower doses of corticosteroids of 80-60 mg per day were applied. In the group of studied patients, 1 person remained in intensive, 10 - refresher and 18 - maintaining therapy. For statistical purposes, patients were divided into two groups: group I consisted of 11 patients receiving refresher treatment from 1 to 2 years (which included 1 patient remaining for 3 months on intensive therapy) and group $\|-18$ people (including 5 with PF), continued treatment with CS maintaining dose for 3 to 13 years. The tests were performed only in patients who did not receive drugs to prevent development of osteopenia/osteoporosis. Due to a small group of patients with pemphigus foliaceus (5), it was not considered separately. The duration of the corticosteroid therapy in all patients ranged from 3 months to 13 years (an average of 5.5 years).

The project work has been approved by the Commission of the Bioethics Medical University in Lodz (RNN/395/09/KB). All persons involved in the medical experiment were informed of the purpose and principles of work. The research was conducted after obtaining written consent from patients and healthy volunteers.

Blood samples of $5 \mathrm{ml}$ were collected in disposable test tubes from patients and controls. After centrifugation, all serum samples were stored at $-20^{\circ} \mathrm{C}$ until analyzed (for a period not exceeding 30 days). The concentration of sRANKL was evaluated by immunoenzymatic assay using a commercially available set produced by BioVendor. Osteocalcin and osteoprotegerin levels were assessed by ELISA (enzyme-linked immunosorbent assay) strictly according to the manufacturer's recommendations (QUIDEL).

\section{Statistical analysis}

Statistical analysis was performed using Statistica, version 9.0 software (Statsoft, Poland). The Mann-Whitney $U$ test was used to compare interval variables between 2 independent groups. For comparisons of average values in groups I and II, Kruskal-Wallis test was used. In all calculations, a $p$ value less than 0.05 was regarded as statistically significant. The results are given as averages and standard deviations.

\section{Results}

In patients with pemphigus, the mean osteoprotegerin concentration was between 12.60 and $40.60 \mathrm{pmol} / /$ (mean: $22.30 \mathrm{pmol} / \mathrm{l}$ ), but in controls, the value was found to be between 11.50 an $21.60 \mathrm{pmol} / \mathrm{l}$ (mean: 18.63 $\mathrm{pmol} / \mathrm{l})$. The mean concentration of this protein was 
Table 1. OPG levels in patients and controls

\begin{tabular}{lcccccc}
\hline Group & $\boldsymbol{N}$ & Mean & Median & Minimum & Maximum & SD \\
\hline Patients & 29 & 22.3034 & 21.1000 & 12.6000 & 40.6000 & 5.7087 \\
\hline Controls & 24 & 18.6333 & 18.3000 & 11.5000 & 26.1000 & 3.66638 \\
\hline
\end{tabular}

Table 2. OPG in females and males with pemphigus

\begin{tabular}{llccccc}
\hline Gender & $\boldsymbol{N}$ & Mean & Median & Minimum & Maximum & SD \\
\hline Females & 17 & 21.5941 & 19.5000 & 16.8000 & 29.3000 & 4.2766 \\
\hline Males & 12 & 23.3083 & 22.6000 & 12.6000 & 40.6000 & 7.3805 \\
\hline
\end{tabular}

Table 3. OPG in females and males in the control group

\begin{tabular}{lcccccc}
\hline Gender & $\boldsymbol{N}$ & Mean & Median & Minimum & Maximum & SD \\
\hline Females & 16 & 18.2688 & 18.3000 & 11.5000 & 24.4000 & 3.38402 \\
\hline Males & 8 & 19.3625 & 18.9000 & 13.3000 & 26.1000 & 4.32631 \\
\hline
\end{tabular}

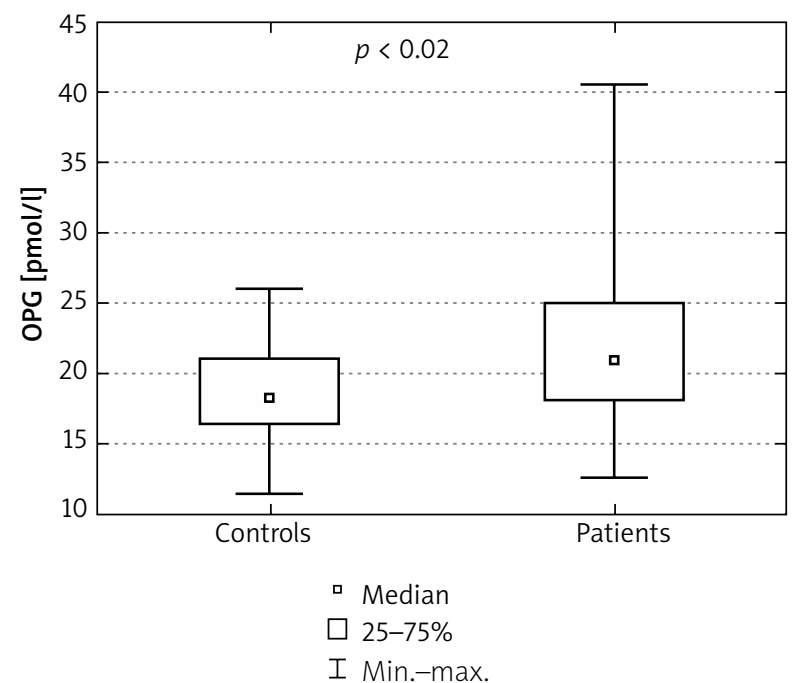

Figure 1. Comparison of the mean levels of OPG in controls and patients

found to be up to $16.46 \%$ higher in pemphigus patients compared with those in the control group $(p<0.02)$. The results are presented in Table 1 and Figure 1.

A comparison of mean osteoprotegerin values in men and women in the group of pemphigus patients as well as in the control group showed no statistically significant differences (Tables 2 and 3, Figure 2). However, the average concentration of OPG in female patients treated with corticosteroid therapy was significantly higher than that found in healthy controls $(p<0.05)$. Similar comparisons were not observed in the group of males $(p>0.05)$ (Figure 3). Analyzing the group studied, depending on the duration of treatment, it has been shown that in group I (treated for 3 months to 2 years) the average concentration of OPG was $22.87 \mathrm{pmol} / \mathrm{l}$, while in the second group

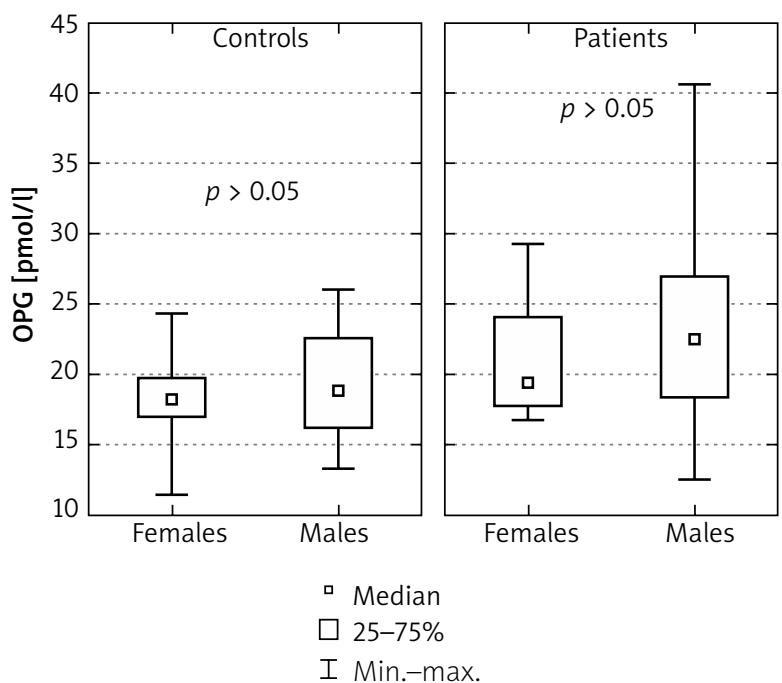

Figure 2. Comparison of the mean levels of OPG in controls (females vs. males) and patients (females vs. males)

(3-13 years) - $21.95 \mathrm{pmol} / \mathrm{l}$ and the differences were not statistically significant $(p=0.93)$.

Concentrations of SRANKL ranged from 270.80 $\mathrm{pmol} / \mathrm{l}$ to $997.30 \mathrm{pmol} / \mathrm{l}$ in pemphigus patients while they ranged from $213.50 \mathrm{pmol} / \mathrm{l}$ to $572.10 \mathrm{pmol} / \mathrm{l}$ in the control group. The mean concentration of this parameter was significantly higher in the corticosteroid-treated group (539.05 pmol/l) than in the control group (394.14 pmol/l). The difference was $26.88 \%$, which was statistically significant $(p<0.001)$ (Table 4 , Figure 4). No differences with regard to the gender of the subjects were found in these compared groups (patients/controls) $(p>0.05)$ (Tables 5 and 6, Figure 5). The mean concentrations of SRANKL in both women and men of the patient group were significantly higher than those found in their 


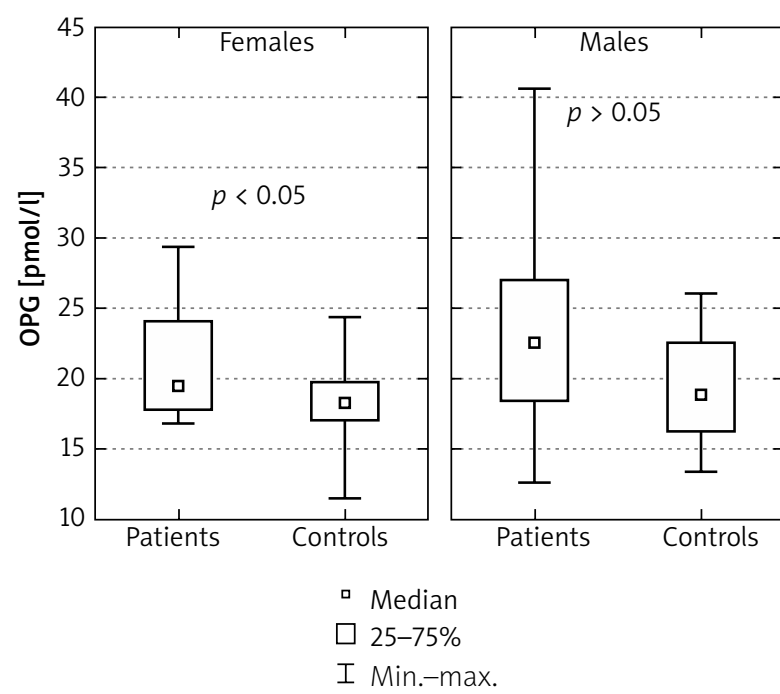

Figure 3. Comparison of the mean levels of OPG in females (patients vs. controls) and in males (patients vs. controls)

gender-compatible control group ( $p<0.002$ for men; $p<0.02$ for women) (Figure 6). However, no statistically significant differences $(p=0.93)$ between the average concentration of sRANKL in group I (560.93 pmol/l) and II (525.68 pmol/l) have been found.

In corticosteroid-treated patients, the mean level of osteocalcin was $22.14 \mathrm{ng} / \mathrm{ml}$. In comparison to the normal limits (12-41 ng/ml for premenopausal women, 20$48 \mathrm{ng} / \mathrm{ml}$ for postmenopausal women and $11-43 \mathrm{ng} / \mathrm{ml}$ for men), this protein was found to be below the recommended levels in 7 out of 29 patients: 4 females and 3 males. The mean concentration of the same marker in a group of healthy people was $27.01 \mathrm{ng} / \mathrm{ml}$, and the values were within normal limits for all of the people in this group. The patient group demonstrated a significantly lower concentration of osteocalcin of up to $18.03 \%$ $(p<0.05)$ (Table 7, Figure 7). When taking gender into account, no statistically significant differences in osteocalcin levels were found between men and women in either compared population (Tables 8 and 9, Figure 8). However, in men with pemphigus, average osteocalcin levels were found to be significantly lower than those in the control

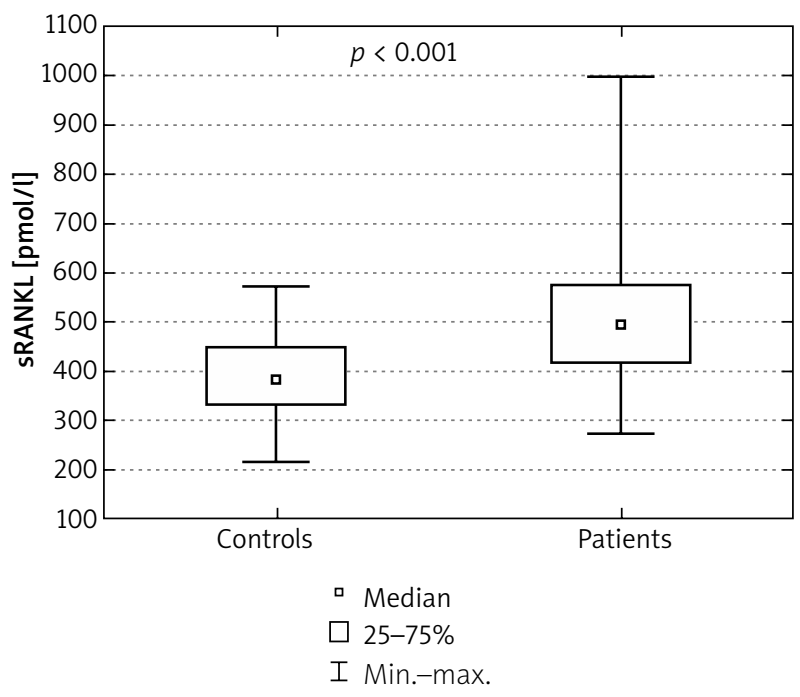

Figure 4. Comparison of the mean levels of SRANKL in controls and patients

group ( $p<0.004)$. No similar relations have been demonstrated in women (patients vs. controls) (Figure 9). Taking into account the duration of therapy it has been shown that in group I (treated for 3 months to 2 years) the mean concentration of osteocalcin was $21.85 \mathrm{ng} / \mathrm{ml}$, while in group II (3-13 years) - $22.32 \mathrm{ng} / \mathrm{ml}$, and those differences were not statistically significant $(p=0.97)$.

\section{Discussion}

Glucocorticoids, widely used to treat many skin conditions, including pemphigus, are also one of the most common causes of secondary osteoporosis, or chronic, progressive disorders of outstanding low bone mass and microarchitectural degradation of bone tissue. This leads to weakening of bone strength and consequently to an increased risk of fractures [14, 15]. According to the American Society of Rheumatology, chronic corticosteroid treatment is defined as taking a prednisone dose equal to or greater than $5 \mathrm{mg} /$ day for a period longer than 3 months [16]. Data from the literature indicate that the limit below which no clinically significant risk of bone

Table 4. sRANKL in patients and controls

\begin{tabular}{lcccccc}
\hline Group & N & Mean & Median & Minimum & Maximum & SD \\
\hline Patients & 29 & 539.0517 & 495.8000 & 270.8000 & 997.3000 & 167.3290 \\
\hline Controls & 24 & 394.1375 & 384.0500 & 213.5000 & 572.1000 & 83.52644 \\
\hline
\end{tabular}

Table 5. sRANKL in females and males with pemphigus

\begin{tabular}{llccccc}
\hline Gender & $\boldsymbol{N}$ & Mean & Median & Minimum & Maximum & SD \\
\hline Females & 17 & 559.7471 & 520.2000 & 390.9000 & 997.3000 & 177.0017 \\
\hline Males & 12 & 509.7333 & 462.5500 & 270.8000 & 840.7000 & 155.2425 \\
\hline
\end{tabular}




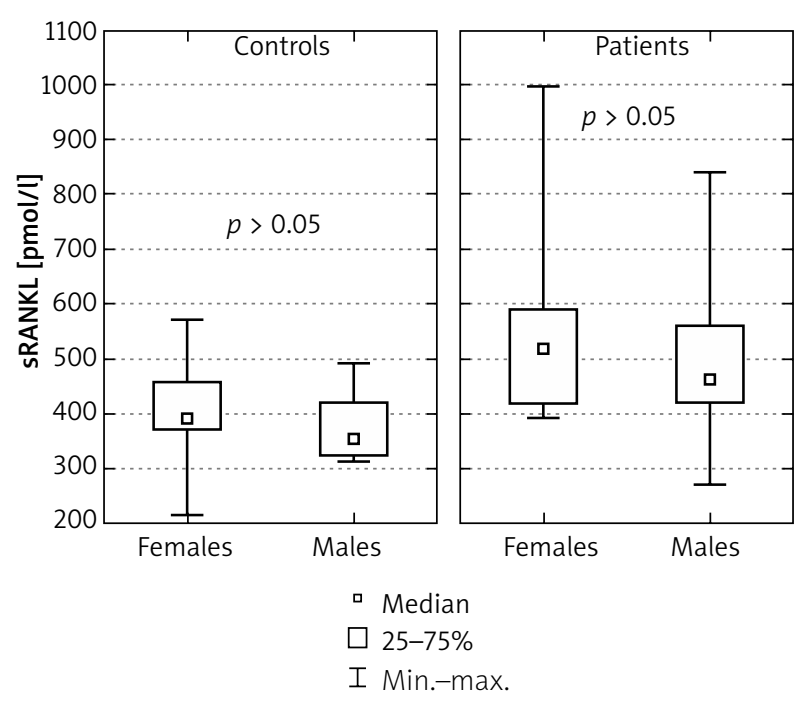

Figure 5. Comparison of the mean levels of SRANKL in controls (females vs. males) and patients (females vs. males)

loss occurs corresponds to $7.5 \mathrm{mg}$ of prednisolone a day for a period of not more than 6 months $[17,18]$. Some authors, however, underline that lower doses of corticosteroids may significantly reduce bone density [8].

It is worth stressing that pemphigus patients require treatment with much higher doses of immunosuppressive preparations (prednisone $100 \mathrm{mg} /$ day and cyclophosphamide $100 \mathrm{mg} /$ day), which should be progressively reduced over many years. It is estimated that a significant loss of bone mass and bone fractures are detected in $30-50 \%$ of pemphigus patients $[8,17]$. It affects the trabecular bone to a greater extent than the cortical bone, and is especially common in the vertebrate shafts in the lumbar spine, the proximal epiphysis of the femur and the distal radius bone $[18,19]$.

The regulation of the bone remodeling process is a result of the interaction of many factors: both mechanical pressure and the chemical interaction of various hormones and cytokines. The key role in maintaining a balance between the processes of bone creation and resorption played by proteins belonging to the family of cytokines and TNF receptors was described in the past

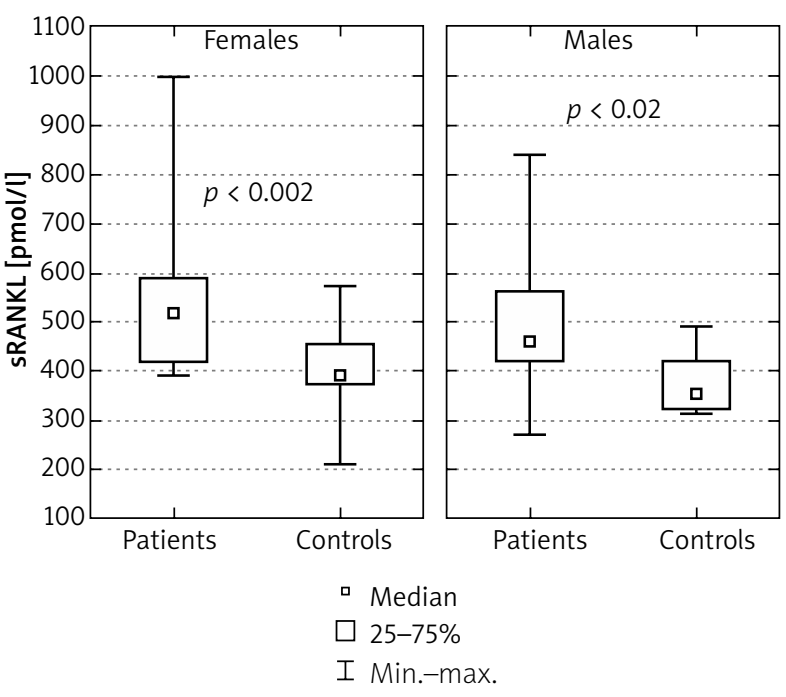

Figure 6. Comparison of the mean levels of sRANKL in females (patients vs. controls) and in males (patients vs. controls)

decade. The most important proteins are the nuclear factor- $\kappa \beta$ activation receptor (RANK), its ligand (RANKL) and osteoprotegerin. In the functioning mechanism of bone remodeling, the binding of the RANK ligand to RANK is essential for osteoclast formation, function and survival. Osteoprotegerin, a decoy receptor that prevents the RANK ligand binding to RANK, may have the ability to block the destruction of bone tissue $[8,12,20]$.

Our studies revealed greater increases of RANKL in pemphigus patients compared to healthy volunteers, regardless of gender. The significantly higher values of this protein seen in both men and women, are probably a result of prolonged treatment with high doses of corticosteroids. Similar observations were published by Yosipovitch Summey and Raisz; the authors suggest that an increased concentration of SRANKL is caused by chronic corticosteroid treatment, which contributes to the severity of the bone resorption process [8, 12].

Moreover, our study also revealed elevated concentrations of serum osteoprotegerin in patients, compared to those found in control group subjects. Significantly higher values were present in a group of women. How-

Table 6. SRANKL in females and males in the control group

\begin{tabular}{lcccccc}
\hline Gender & $\boldsymbol{N}$ & Mean & Median & Minimum & Maximum & SD \\
\hline Females & 16 & 403.8250 & 391.3500 & 213.5000 & 572.1000 & 91.54361 \\
\hline Males & 8 & 374.7625 & 354.8500 & 311.9000 & 491.4000 & 65.74316 \\
\hline
\end{tabular}

Table 7. Osteocalcin levels in patients and controls

\begin{tabular}{llllllr}
\hline Group & $\boldsymbol{N}$ & Mean & Median & Minimum & Maximum & SD \\
\hline Patients & 29 & 22.1379 & 22.9000 & 6.5000 & 38.9000 & 9.5159 \\
\hline Controls & 24 & 27.0125 & 27.1000 & 17.1000 & 38.2000 \\
\hline
\end{tabular}




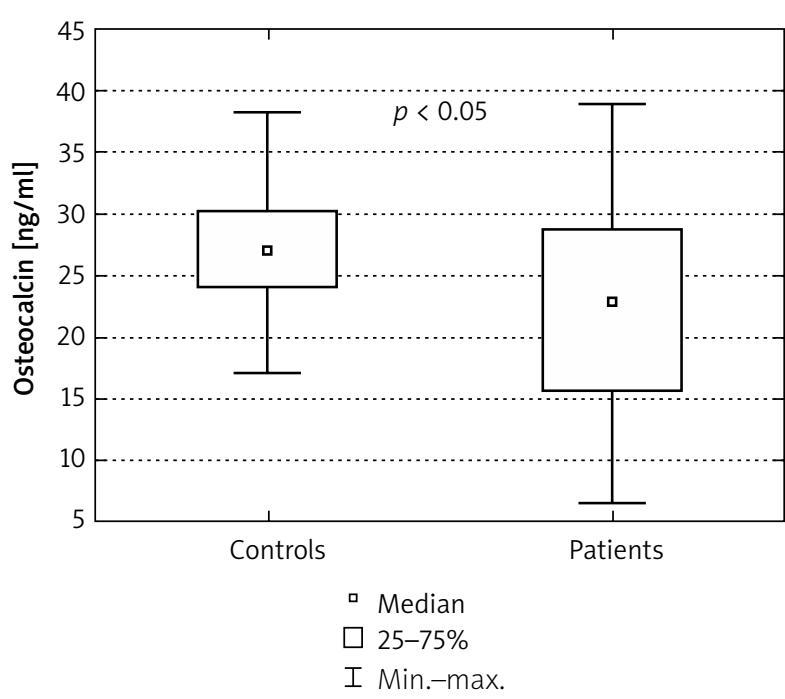

Figure 7. Comparison of mean levels of osteocalcin in controls and patients

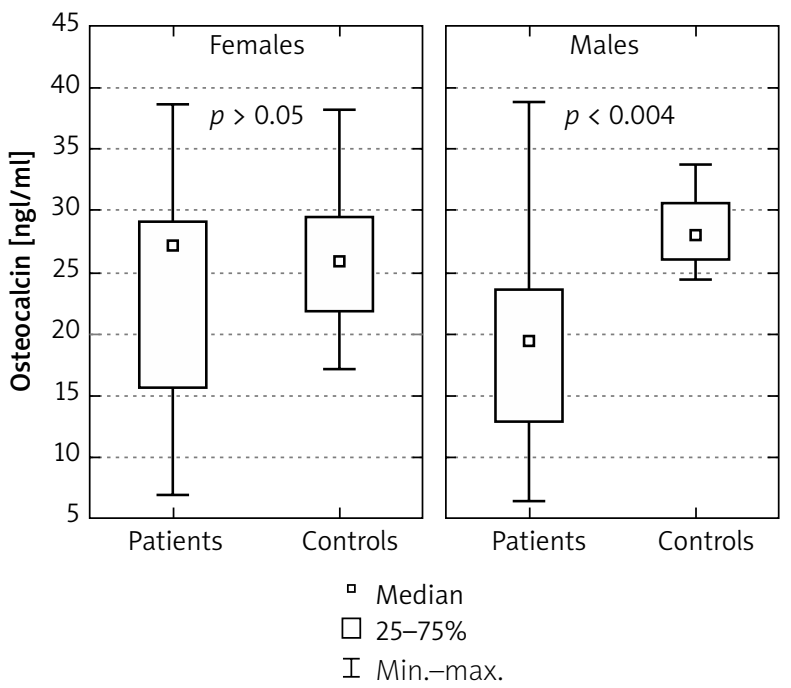

Figure 9. Comparison of the mean levels of osteocalcin in females (patients vs. controls) and in males (patients vs. controls)

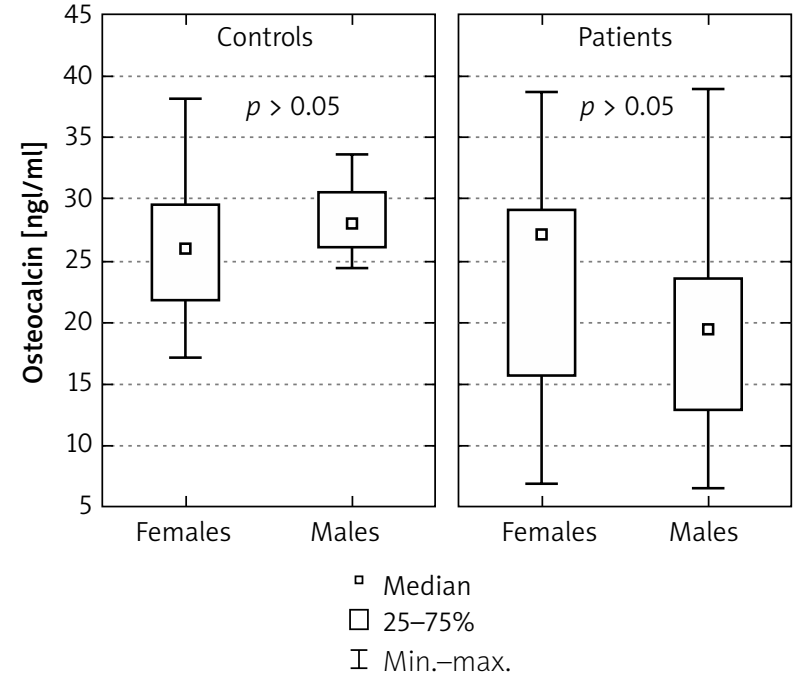

Figure 8. Comparison of the mean levels of osteocalcin in controls (females vs. males) and patients (females vs. males)

ever, as corticosteroid therapy is usually connected with OPG reduction, the higher level seen in our group could be explained as a result of a compensatory response to corticosteroid-induced bone resorption. The organism can launch the body's defense mechanisms, as seen by an increase in OPG. It is well known that not only the applicable treatment has a significant impact on the RANK/RANKL/OPG pathway. In postmenopausal women, estrogens decline and RANK ligand expression increases, which causes greater osteoclast activity, which in turn results in bone loss and weakened bone architecture [21]. In our study population, 15 out of the 17 tested women was in the menopause. The fastest loss of bone mass is observed during the first few years after menopause and according to the Polish Osteoporosis Foundation, it can reach a value of up to 20\% throughout the first 5 years. It is generally accepted that the speed of bone loss is twice as great in women than in men of the same age $[22,23]$. An imbalance between the relative concentrations of RANKL and OPG as a result of the exhaustion of the loopback mechanism contributes to the competitive

Table 8. Osteocalcin levels in females and males with pemphigus

\begin{tabular}{lcccccc}
\hline Gender & $\boldsymbol{N}$ & Mean & Median & Minimum & Maximum & SD \\
\hline Females & 17 & 24.2882 & 27.2000 & 6.9000 & 38.7000 & 9.6285 \\
\hline Males & 12 & 19.0917 & 19.5000 & 6.5000 & 38.9000 & 8.8533 \\
\hline
\end{tabular}

Table 9. Osteocalcin levels in females and males in the control group

\begin{tabular}{lcccccc}
\hline Gender & $\boldsymbol{N}$ & Mean & Median & Minimum & Maximum & SD \\
\hline Females & 16 & 26.2938 & 26.0000 & 17.1000 & 38.2000 & 5.97968 \\
\hline Males & 8 & 28.4500 & 28.0500 & 24.4000 & 33.7000 & 3.09100 \\
\hline
\end{tabular}


advantage of osteoclast activity and consequently, the development of osteoporosis.

The results of the present study reveal a lower mean concentration of osteocalcin in patients with pemphigus compared to the control group, the difference being statistically significant. A significant difference ( $p<0.004$ ) was only found in a group of male patients. The decreased levels of osteocalcin confirm the impaired activity of osteoblasts, participating in the process of bone building and mineralization, which is exacerbated by the loss of bone mass. Some authors indicate a high probability of developing serious disturbances of bone metabolism depending on corticosteroid treatment duration, and the amount of doses in both daily and cumulative ones. Our research did not reveal a similar relation [24]. Abnormal bone mineralization, of which the exponents are the deviation of OPG, SRANKL, osteocalcin, occurred in our patients irrespective of the duration of corticosteroid (CS) therapy. Other authors emphasize that the risk of bone loss increases rapidly in the first 3-6 months of treatment. In subsequent years, the application of steroid preparations, and the destruction of bone tissue is definitely slower and it is about 3\% per year $[8,25]$. In our study, it was not possible to calculate cumulative doses of glucocorticosteroids in individual patients. The difficulties resulted from the long-term therapy (average 5.5 years), the control of patients in the different health care settings, and incomplete medical records. No parameters reflecting the negative impact of corticosteroid treatment on bone tissue other than the deviations seen in the present study, such as limitation of joint mobility, pain or pathological bone fractures, were reported in the analyzed group. According to many studies, the loss of bone mass progresses quickly and dynamically, but for a long time is asymptomatic and crafty, leads to the development of secondary osteoporosis and increased risk of fractures, especially of the long bones and vertebrae of the spine $[24,26]$. It is not without reason that osteoporosis is called the silent thief of the bone [27]. So it is crucial to increase the awareness of doctors regarding the appropriate monitoring of the implementation of preventive procedures for all patients receiving chronic corticosteroid therapy. Unfortunately, epidemiological studies show that more than half of the patients treated chronically with corticosteroids, for various indications, is not diagnosed as osteopenia/osteoporosis and only a few receive appropriate prophylactic treatment [23, 24]. According to Polish standards, it is indicated that the densitometry test should be conducted before starting the long-term glucocorticosteroid treatment, repeated afterwards every 6-12 months [28]. This procedure allows the presumptive identification of people at risk of osteoporosis, and the monitoring of preventive and therapeutic action. Patients whose are planned for CS should receive 1000-1500 mg per day of calcium and 400-800 IU per day of vitamin D [29]. The proper control of metabolic processes is crucial for maintaining adequate bone macro- and microarchitecture and appropriate bone function.

\section{Acknowledgments}

This work was supported by the grant from Medical University of Lodz, Poland No 503/1-152-01/503-01. Funded by the European Union from the European Social Fund and the state budget under the Integrated Regional Operational Programme.

\section{References}

1. Murrell DF, Dick S, Ahmed AR, et al. Consensus statement on definitions of disease, end points, and therapeutic response for pemphigus. J Am Acad Dermatol 2008; 58: 1043-6.

2. Torzecka JD. Pemphigus - immunological and genetic studies [Polish]. Medical University of Lodz, 2004.

3. Bystryn JC, Steinman NM. The adjuvant therapy of pemphigus. An update. Arch Dermatol 1996; 132: 203-12.

4. Carson PJ, Hameed A, Ahmed AR. Influence of treatment on the clinical course of pemphigus vulgaris. J Am Acad Dermatol 1996; 34: 645-52.

5. Harman KE, Albert S, Black MM. Guidelines for the management of pemphigus vulgaris. Br J Dermatol 2003; 149: 926-37.

6. Kanwar AJ, Dhar S. Factors responsible for death in patients with pemphigus. J Dermatol 1994; 21: 655-9.

7. Mazziotti G, Angeli A, Bilezikian JP, et al. Glucocorticoid-induced osteoporosis: an update. Trends Endocrinol Metab 2006; 17: 144-9.

8. Summey BT, Yosipovitch G. Glucocorticoid-induced bone loss in dermatologic patients: an update. Arch Dermatol 2006; 142: 82-90.

9. Saag KG. Glucocorticoid-induced osteoporosis. Endocrinol Metab Clin North Am 2003; 32: 135-57.

10. Stazi C, Stazi F. Pemphigus vulgaris: severe osteoporosis during cortisone therapy. Description of a case. Clin Ter 1991; 137: 9-20.

11. Chmurova N, Svecova D. Pemphigus vulgaris: a 11-year review. Bratisl Lek Listy 2009; 110: 500-3.

12. Raisz LG. Pathogenesis of osteoporosis: concepts, conflicts, and prospects. J Clin Invest 2005; 115: 3318-25.

13. Calvo MS, Eyre DR, Gundberg CM. Molecular basis and clinical application of biological markers of bone turnover. Endocrine Rev 1996; 17: 333-8.

14. WHO Study Group. Assessment of fracture risk and its application to screening for postmenopausal osteoporosis. Osteoporos Int 1994; 4: 368-81.

15. Czerwiński E, Lorenc R, Marcinkowska-Suchowierska E, et al. The position of the Polish Society of Osteoarthrology and Osteoporotic Multidisciplinary Forum on the standards of diagnosis and treatment of osteoporosis in Poland [Polish]. Med Dypl 2006; Suppl. 4: 1-12.

16. American College of Rheumatology Ad Hoc Committee on Glucocorticoid-Induced Osteoporosis: Recommendations for the prevention and treatment of glucocorticoid-induced osteoporosis. 2001 update. Arthritis Rheum 2001; 44: 1496503.

17. Sambrook PN. Corticosteroid osteoporosis: practical implications of recent trials. J Bone Miner Res 2000; 15: 1645-9. 
18. Eastell R, Reid DM, Compston J, et al. Consensus Group on management of glucocorticoid-induced osteoporosis: an update. J Intern Med 1998; 244: 271-92.

19. Cisło M, Kobierczyka M. Glucocorticoid osteoporosis: pathogenesis, diagnosis and treatment [Polish]. Przegl Dermatol 2004; 91: 7-13.

20. Vega D, Maalouf NM, Sakhaee K. The role of RANK/RANKL/ OPG: clinical implications. J Clin Endocrinol Metab 2007; 92: 4514-21.

21. Riggs BL, Khosla S, Melton LJ 3rd. A unitary model for involutional osteoporosis: estrogen deficiency causes both type I and type II osteoporosis in postmenopausal women and contributes to bone loss in aging men. J Bone Miner Res 1998; 13: 763-73.

22. Looker AC, Orwoll ES, Johnton CC Jr, et al. Prevalence of low femoral bone density in older U. S. adults from NHANES III. J Bone Miner Res 1997; 12: 1761-8.

23. Skowrońska-Jóźwiak E, Lewiński A. Osteoporosis in men and women - similarities and differences [Polish]. Pol J Endocrinol 2006; 3: 260-6.

24. Van Staa TP, Leufkens HG, Abenhaim L. Oral corticosteroids and fracture risk: relationship to daily and cumulative doses. Rheumatology 2000; 39: 1383-89.

25. Van Staa TP, Leufkens HG, Cooper C. The epidemiology of corticosteroid-induced osteoporosis: a meta-analysis. Osteoporos Int 2002; 13: 777-87.

26. Bell R, Carr A, Thompson P. Managing corticosteroid induced osteoporosis in medical outpatients. J R Coll Physicians Lond 1997; 31: 158-61.

27. Olejniczak T, Opala T, Woźniak J, et al. Osteoporosis - epidemiology, pathogenesis, diagnosis and treatment [Polish] Przew Lek 2000; 9: 39-46.

28. Polish team of 23 experts: Polish recommendations for the prevention of vitamin D deficiency - 2009 [Polish]. Standardy Medyczne 2009; 6: 875-9.

29. Karlińska M, Waszczykowska E, Torzecka JD. Bone metabolism disorders and glucocorticoid therapy in patients with pemphigus [Polish]. Postep Derm Alergol 2010; 27: 484-9. 